\title{
Cell cycle control and seed development
}

\author{
Ricardo A. Dante ${ }^{1}$, Brian A. Larkins ${ }^{2,3}{ }^{*}$ and Paolo A. Sabelli ${ }^{3}$ \\ ${ }^{1}$ Embrapa Agricultural Informatics, Campinas, Brazil \\ 2 Department of Agronomy and Horticulture, University of Nebraska, Lincoln, NE, USA \\ ${ }^{3}$ School of Plant Sciences, University of Arizona, Tucson, AZ, USA
}

\section{Edited by:}

Neelima Roy Sinha, University of California, Davis, USA

\section{Reviewed by:}

A. Mark Settles, University of Florida, USA

Pablo Daniel Jenik, Franklin \&

Marshall College, USA

\section{*Correspondence:}

Ricardo A. Dante, Embrapa

Agricultural Informatics, Avenida

André Tosello 209, Campinas,

São Paulo 13083-886, Brazil

e-mail: ricardo.dante@embrapa.br;

Brian A. Larkins, Department of

Agronomy and Horticulture, University of Nebraska, 230J Whittier Research

Center, 2200 Vine Street, Lincoln,

NE 68583-0857, USA

e-mail: blarkins2@unl.edu;

Paolo A. Sabelli, School of Plant

Sciences, University of Arizona, 303

Forbes, 1140 East South Campus

Drive, Tucson, AZ 85721-0036, USA

e-mail: psabelli@ag.arizona.edu
Seed development is a complex process that requires coordinated integration of many genetic, metabolic, and physiological pathways and environmental cues. Different cell cycle types, such as asymmetric cell division, acytokinetic mitosis, mitotic cell division, and endoreduplication, frequently occur in sequential yet overlapping manner during the development of the embryo and the endosperm, seed structures that are both products of double fertilization. Asymmetric cell divisions in the embryo generate polarized daughter cells with different cell fates. While nuclear and cell division cycles play a key role in determining final seed cell numbers, endoreduplication is often associated with processes such as cell enlargement and accumulation of storage metabolites that underlie cell differentiation and growth of the different seed compartments. This review focuses on recent advances in our understanding of different cell cycle mechanisms operating during seed development and their impact on the growth, development, and function of seed tissues. Particularly, the roles of core cell cycle regulators, such as cyclindependent-kinases and their inhibitors, the Retinoblastoma-Related/E2F pathway and the proteasome-ubiquitin system, are discussed in the contexts of different cell cycle types that characterize seed development. The contributions of nuclear and cellular proliferative cycles and endoreduplication to cereal endosperm development are also discussed.

Keywords: cell division, cotyledon, cyclin-dependent kinase, embryo, endoreduplication, endosperm, retinoblastoma-related, seed coat

\section{INTRODUCTION}

\section{SEED DEVELOPMENT PHASES}

Angiosperms reproduce sexually via the production of seeds, which are typically derived from the fertilization of ovules, or asexually via apomixis. Mature seeds characteristically contain three major structures: a sporophyte (the embryo), nutrient storage tissues or organs (the endosperm and/or the embryonic cotyledons), which support embryogenesis and early post-embryonic sporophyte development, and a protective structure (the seed coat or testa). A prominent triploid endosperm is typically present in mature monocot seeds, while most of its cells are consumed during dicot seed development. The seed coat is a maternal structure derived from the ovule integuments that functions in seed protection, dormancy, germination, and, in some dicot species like legumes (Fabaceae or Leguminoseae family), transiently in nutrient storage. In the monocot Poaceae family (grasses), the seed coat is fused to the pericarp (the fruit coat). The maternal plant makes significant contributions to seed production by providing nutrients, conveying hormonal and environmental cues and imposing mechanical constraints on the floral structures within which seeds develop. Consequently, seed production is influenced by a range of zygotic, sporophytic, and environmental factors (Egli, 2006).

The size of a multicellular organism, its organs and tissues depend on the number and size of constituent cells. Cell number, in turn, depends on the rate of cell division, the number of dividing cells, and the duration of the cell proliferation phase during development, while the size of non-dividing cells is influenced by cell growth and cell expansion (defined as increases in cell macromolecular mass and cell volume, respectively; Sugimoto-Shirasu and Roberts, 2003). In plants, cell number generally seems to make a larger contribution than cell size to the size of comparable organs (reviewed by Mizukami, 2001). However, seed size and weight are highly influenced by cell size via the growth and expansion brought about by massive accumulation of storage compounds (proteins, lipids, and/or carbohydrates) and water intake by cotyledon or endosperm cells. In cereal and legume crops, seed growth and development typically comprise three partially overlapping phases: an initial lag phase initiated at fertilization and characterized by cell proliferation and minimal dry weight gain (phase I); seed filling, a linear phase of large dry weight gain associated with cell enlargement and accumulation of storage compounds (phase II); and a final phase of reduced dry weight gain associated with desiccation and dormancy (phase III; Egli, 2006). In phase I, various seed tissues and domains are specified and established, including the vital transfer cells, a filial conduit with the mother plant vascular tissue that nourishes the developing seed. Phase I is also characterized by uptake of sucrose, which is rapidly converted to hexoses via cell wall-bound invertase activity. Even though phase I is critical for seed development and grain yield, its contribution is indirect, as the cells generated in this phase are very small and contribute little to seed biomass. However, 
during phase II most of the endosperm or cotyledon cells generated in phase I accumulate storage compounds. Thus, phase II is characterized by cell enlargement due to cell growth and cell expansion, and a peak in seed water content (Egli, 2006). In storage cells of the cereal endosperm and legume cotyledons, phase II is also characterized by endoreduplication (also known as endopolyploidization, endocycling, or endoreplication), a type of cell cycle that leads to polyploidy. During phase III, water concentration decreases dramatically and physiological maturity is reached.

\section{CELL CYCLE TYPES OCCURRING DURING SEED DEVELOPMENT}

Briefly, the prototypical mitotic cycle consists of a DNA replication phase (S-phase), and a chromosome condensation and sister chromatid segregation phase (M-phase), which are preceded by G1 and G2 gap phases, respectively. Typically, this cell cycle is associated with cell division, and $\mathrm{M}$-phase is generally coupled to karyokinesis and cytokinesis, which generate daughter cells with chromosome number and nuclear DNA content identical to those of their mother cell. However, in several plant tissues, cell types, and developmental stages, alternative cell cycle types can occur. In the context of seed development, frequently these are acytokinetic mitosis and endoreduplication (Figure 1). In acytokinetic mitosis, the mitotic cell cycle is coupled to karyokinesis in the absence of cytokinesis, thus producing a syncytium or multinucleate cell. Endoreduplication is characterized by recurrent and alternating gap and S-phase, without intervening sister chromatid segregation, karyokinesis and cytokinesis, thus resulting in polyploid cells with an unaltered number of chromosomes, but with each chromosome containing multiple chromatids (reviewed by Edgar et al., 2014). All these different cell cycle types influence the growth and development of seed structures. Early in development, asymmetric cell divisions in the embryo generate polarized daughter cells that take on diverse differentiation paths, and rapid nuclear proliferation and cellularization in the endosperm establish the initial cell populations that occupy the embryo sac. Subsequent intense cell proliferation, coupled to cell differentiation, essentially produces all the embryo and endosperm cell types and tissues.
A

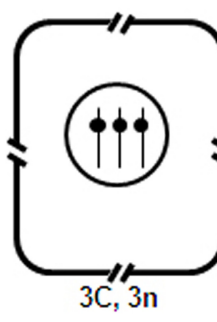

C

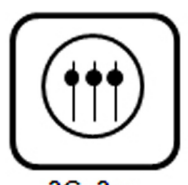

3C, 3n

$\mathbf{E}$
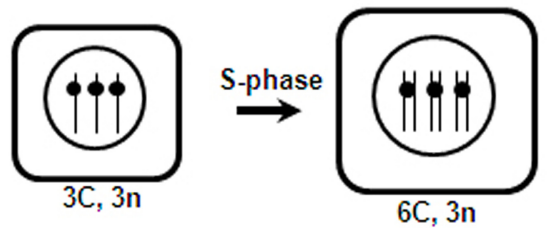

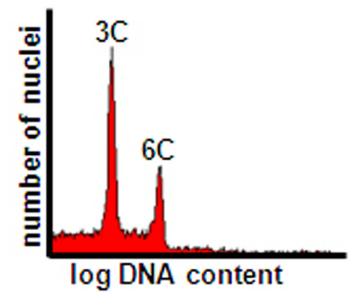

D

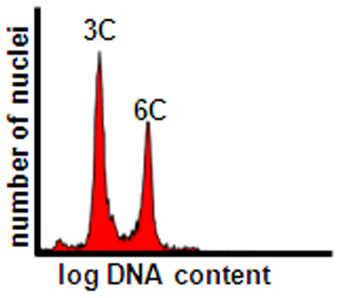

$\mathbf{F}$

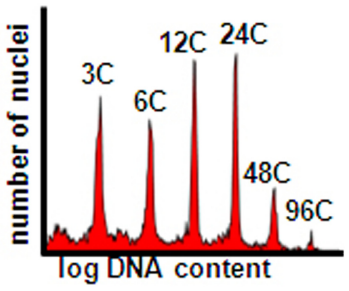

FIGURE 1 | Cell cycle types occurring during seed development. Triploid endosperm mother cells (with two maternal and one paternal chromosomal complements) are shown as an example. A hypothetical haploid number $n=1$ is assumed for simplicity. (A) Acytokinetic mitosis of endosperm nuclei within the embryo sac central cell, resulting in a syncytium; (C) Cell proliferation through mitotic cell division following syncytium cellularization; (E) Endoreduplication of inner endosperm starchy cells. Cell number, size, DNA content, and chromosome number correspond to one complete cell cycle round comprising S-phase and accompanying M-phase and karyokinesis $(\mathbf{A}, \mathbf{C})$ and cytokinesis $\mathbf{( C )}$, and two complete endoreduplication cycle rounds (each comprising S-phase not followed by M-phase, karyokinesis and cytokinesis) (E). Interrupted cell boundaries in (A) indicate the large size of the embryo sac central cell. $C$ and n, DNA content and chromosome number of a haploid cell, respectively. (B,D,F) show typical nuclear flow-cytometric profiles obtained for tissues undergoing asynchronous, iterative acytokinetic mitosis, mitotic cell division, and endoreduplication cycles, respectively. 
Finally, endoreduplication occurs, which is inherently associated with cell enlargement and accumulation of storage compounds in specialized cotyledon or endosperm cells.

Seed biology aspects such as comparative development and anatomy of seed structures and their underlying signaling networks were reviewed in-depth recently (Sabelli and Larkins, 2009b; Nowack et al., 2010; Lau et al., 2012; Sabelli, 2012b). Likewise, the role of cell cycle regulation in plant growth and development has also been reviewed thoroughly elsewhere (De Veylder et al., 2011; Heyman and De Veylder, 2012; Edgar et al., 2014; Sabelli, 2014). Hence, we focus on recent findings that clarify the role of core cell cycle regulators and different cell cycle types in the development, growth, and function of seed structures.

\section{CELL CYCLE CONTROL AND CORE REGULATORS IN PLANTS: AN OVERVIEW CYCLIN-DEPENDENT KINASES AND CYCLINS}

In eukaryotes, cell cycle progression is controlled by the periodic activity of various heterodimeric threonine/serine protein kinases composed of catalytic and regulatory subunits, a cyclindependent kinase (CDK) and a cyclin, respectively. Plants possess relatively large sets of genes encoding different CDKs and cyclins, which can interact to form a potentially large number of combinations (Van Leene et al., 2011). Plants contain eight types of CDK-like proteins (reviewed by Dudits et al., 2007). Among the major CDKs involved with cell cycle regulation are members of the A-type, which characteristically contain in their cyclininteracting $\alpha$-helix a hallmark PSTAIRE amino acid motif; these function during S-phase and at the G1/S and G2/M transitions. In the plant-specific B-type CDKs, which function primarily at the G2/M transition, the PSTAIRE motif is replaced by PPTALRE (B1-subtype) or PPTTLRE (B2-subtype). D- and F-type CDKs, also known as CDK-activating kinases (CAKs), regulate A- and Btype CDKs through phosphorylation of specific residues (reviewed by Inzé and De Veylder, 2006). Angiosperm genomes possess a cyclin complement of $\sim 50-60$ genes organized into $\sim 10$ types (Wang etal., 2004; La etal., 2006; Hu etal., 2010; Ma etal., 2013). The majority of D-type cyclins are involved in the control of the G1/S transition; A-type cyclins, S-phase, and the G2/M transition; and B-type cyclins, G2/M, and intra-mitotic transitions (Inzé and De Veylder, 2006). CDK/cyclin complexes are subjected to different levels of regulation, including binding by non-catalytic CDK-specific inhibitors (CKIs), activating or inhibitory phosphorylation of CDK subunits, and cell cycle phase-specific cyclin synthesis and proteolysis, the latter of which is mediated by the ubiquitin-proteasome system (UPS; Inzé and De Veylder, 2006). A simplified diagram depicting some major molecular mechanisms of the plant cell cycle is shown in Figure 2.

\section{THE RETINOBLASTOMA-RELATED PATHWAY}

In higher eukaryotes, proteins of the retinoblastoma-related (RBR) family are known as repressors of the G1/S transition for their inhibitory effect on heterodimeric E2F/DP transcription factors. These, in turn, control the expression of multiple genes required for this cell cycle transition and S-phase progression, such as those encoding the subunits of the helicase MINICHROMOSOME
MAINTENANCE2-7 (MCM2-7) and the replication processivity factor proliferating cell nuclear antigen (PCNA) complexes (reviewed by Sabelli and Larkins, 2009c). RBR proteins are sequentially phosphorylated and inhibited by different CDK complexes, which relieves the block on E2F/DP-dependent gene expression and results in the transition into S-phase. In plants, CDK complexes containing D- and A-type cyclins seem to phosphorylate and thus inhibit RBR proteins. Grasses possess a more numerous and functionally diverse set of RBR proteins than most dicots, including Arabidopsis thaliana (Sabelli and Larkins, 2006, 2009c). The maize (Zea mays) genome contains at least four RBR genes that are grouped into two distinct types of duplicated genes, exemplified by RBR1 and RBR3 (Sabelli et al., 2005; Sabelli and Larkins, 2006). While $R B R 1$ functions as a repressor of cell cycle progression (Sabelli et al., 2013), RBR3 stimulates the expression of genes encoding MCM2-7 proteins and DNA replication (Sabelli et al., 2009). RBR3 is itself an E2F/DP target whose expression is negatively regulated by RBR1 (Sabelli et al., 2005).

\section{DNA REPLICATION INITIATION FACTORS}

Regulation of DNA replication in plants is generally believed to follow conserved eukaryotic patterns (reviewed by Costas et al., 2011). Initiation of S-phase requires priming of chromatin via the assembly, at origins of replication, of the pre-replication complex consisting of ORIGIN OF REPLICATION COMPLEX (ORC16), CDC6, CDT1, and MCM2-7 proteins. ORC1-6 associate with origins of replication throughout the cell cycle but become sequentially bound by different proteins. Interaction of CDC6 and CDT1 with ORCs during G1 promotes the loading of MCM2-7, effectively licensing the origins for DNA replication (reviewed by Tuteja et al., 2011). These replication origin complexes are activated by CDKs at the G1/S transition, which leads to the recruitment of the replication machinery, the unwinding of DNA through MCMdependent helicase activity, and DNA synthesis with the formation of replication forks. MCM protein complexes are displaced from replication origins as replication forks advance along the DNA, which prevents re-licensing of origins until S-phase and M-phase are completed. In endoreduplication cycles, DNA replication is initiated independently of $\mathrm{M}$-phase, resulting in repeated rounds of DNA synthesis in the absence of mitosis. However, endoreduplication results from specific cell cycle modifications rather than merely uncontrolled activation of replication origins, which would cause over- and incomplete DNA replication (Costas et al., 2011; De Veylder et al., 2011; Sabelli, 2012a).

\section{UBIQUITIN-DEPENDENT PROTEOLYSIS}

Ubiquitin-Proteasome System-mediated proteolysis promotes the controlled destruction of several cell cycle regulators, which is critical for cell cycle phase transitions. Cyclins, CKIs, and other cell cycle regulators are targeted to the proteasome via their selective modification by various ubiquitin-protein ligases. Among the multimeric E3 ubiquitin-protein ligases functioning in plant cell cycle control are the anaphase promoting complex/cyclosome (APC/C), the Skp1/Cullin/F-box complex, and the Cullin-RING Ubiquitin Ligases (Heyman and De Veylder, 2012; Genschik et al., 2013). During late mitosis and most of G1, CDK activity is typically reduced via the targeting of A- and B-type cyclins 


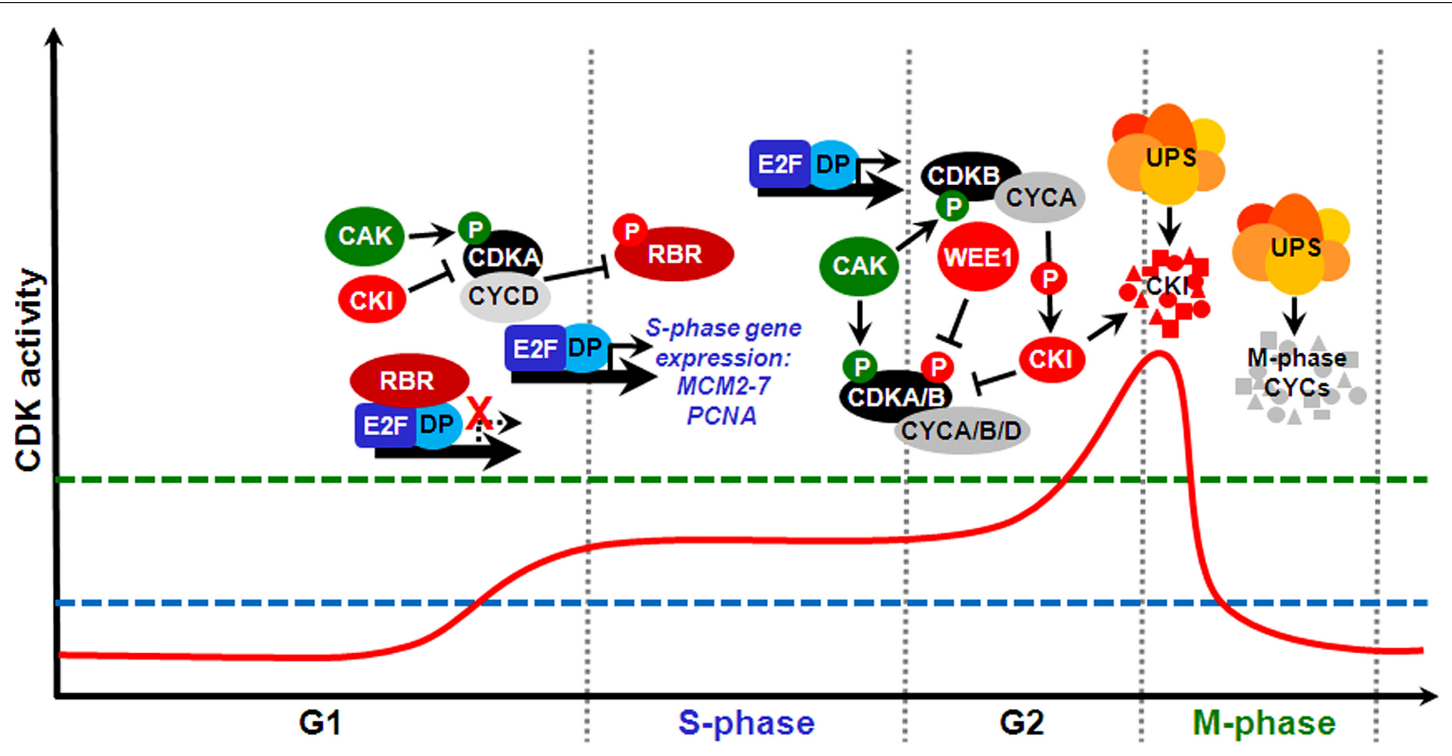

FIGURE 2 |The prototypical mitotic cell division cycle and some key molecular mechanisms that regulate its major transitions in plants. Cell cycle progression through distinct phases is driven by periodic fluctuations of cyclin-dependent kinase (CDK) activity (solid red line). Green and red circles labeled with a $\mathrm{P}$ letter show stimulatory and inhibitory phosphorylation, respectively. For cells to make a transition from G1 into S-phase and execute DNA replication, CDK activity must surpass an S-phase threshold (dashed blue line). A further CDK activity increase above an M-phase threshold (dashed green line) during G2 drives entry into mitosis. Both M-phase exit and origin of replication licensing require CDK activity to be reduced at the end of mitosis and maintained at low levels for most of G1. At the G1/S transition, CDKA/CYCD complexes phosphorylate and thus inactivate retinoblastoma-related (RBR), thus permitting heterodimeric E2F/DP transcription factors to stimulate an S-phase gene expression program, which results in the expression of $\mathrm{MCM} 2-7$ and proliferating cell nuclear antigen (PCNA) genes, among many others. CDKA/CYCD activity is positively and negatively regulated by, respectively, CDK-activating kinase (CAK)-dependent phosphorylation and binding by CKIs. Later in G2, CDK activity requires association with mitotic cyclins and is also stimulated by CAK and inhibited by CKIs. In addition, this CDK activity is inhibited by phosphorylation at specific tyrosine residues by WEE1. Certain CDKs of the B-type, whose expression is E2F/DP-dependent, promote M-phase progression by mechanisms that include interaction with A-type cyclins and stimulation of downstream CDK activity by phosphorylating and targeting certain CKIs for proteolysis by the ubiquitin-proteasome system (UPS) via different E3 ubiquitin ligases. Conversely, mitotic cyclin proteolysis by the UPS, via the APC/C, causes CDK activity to decline sharply, which is required for M-phase exit. to the proteasome by the APC/C. In addition to its roles in the cell division cycle, E3 ligases control endoreduplication cell cycles, those occurring in trichome and root nodule cells being perhaps the best characterized such examples (Cebolla etal., 1999; Roodbarkelari et al., 2010; Heyman and De Veylder, 2012; Genschik et al., 2013).

\section{CDK-SPECIFIC INHIBITORS}

Non-catalytic inhibitors of CDK/cyclin complex activity, generally termed CKIs, have been identified as chief cell cycle regulators in all eukaryotes, and act by obstructing substrate interaction and ATP binding. Two types of CKIs have been identified and characterized in plants: INHIBITOR OF CDC2 KINASE/KIP-RELATED (ICK/KRP) and SIAMESE/SIAMESERELATED (Yi etal., 2014). ICK/KRPs typically bind to complexes containing A-type CDKs and D-type cyclins (Wang et al., 2008), although interaction with B-type CDKs was also reported (Nakai etal., 2006). Plant CKIs are targeted by several E3 ligases for degradation (Zhou etal., 2003; Weinl et al., 2005; Jakoby et al., 2006; Ren et al., 2008; Roodbarkelari et al., 2010). In mitotic cell cycles, ICKs/KRPs are phosphorylated by B1type CDKs and targeted for UPS-mediated degradation, with consequent stimulation of A-type CDK activity and M-phase (Verkest et al., 2005).
The core molecular factors controlling the cell cycle in plants conform, to a large extent, to those identified in other higher eukaryotes. However, plant genomes are often characterized by a larger complement of key cell cycle genes as well as by uniquely possessing certain types of CDKs, E2Fs, and CKIs. The resulting complexity in cell cycle regulatory mechanisms, which appears to have considerable redundancy, may have evolved largely to finetune the cell cycle for the requirements of the sessile life style of plants.

\section{ROLES OF DIFFERENT CELL CYCLES AND REGULATORS IN SEED DEVELOPMENT \\ EMBRYO \\ Cell proliferation, patterning, and morphogenesis during embryo development}

From the first zygotic division through the early globular (8-16 cells) stages, many aspects of embryo development in monocots and dicots are conserved (Lau et al., 2012; Sabelli, 2012b). The zygote divides asymmetrically and generates an apical cell with dense cytoplasm and a large vacuolated basal cell at the chalazal and micropylar ends of the embryo sac, respectively, establishing early embryo polarity and patterning. The apical and basal cells produce, respectively, the proembryo and the suspensor, which has an embryo proper-nourishing function. Afterwards, cell 
proliferation and differentiation occur coordinately to produce all embryo cell types and tissues, including the cotyledon(s), which in dicots accumulate storage compounds and typically occupy a large fraction of the mature seed volume. In dicots, periclinal divisions of the octant cells result in the globular embryo. Subsequently, the heart stage is reached with the characteristic emergence of two cotyledon primordia as opposite lateral extensions of the apical end. Next, cell proliferation and differentiation of the basal cell tier lead to the torpedo stage. As growth proceeds under mechanical constraints imposed by the ovule, the embryo increasingly assumes its typical curved shape. During development, monocot and dicot embryos display increasingly different morphologies. Patterns of cell division and cell lineages usually become less organized in monocot embryos and while two prominent cotyledons emerge in dicots, the origin of the single monocot cotyledon, the scutellum, is spatially more variable. In dicots, cotyledon cells undergo endoreduplication (Dhillon and Miksche, 1983; Lemontey et al., 2000; Rewers and Sliwinska, 2012).

The importance of cell cycle control during embryogenesis extends beyond its most recognizable aspects related to cell division and endoreduplication cycles. In Arabidopsis thaliana and Nicotiana tabacum, disruption of proper developmental patterns through lengthening or impairment of cell division by interfering with CDKA;1 (Hemerly etal., 2000), DNA polymerase $\varepsilon$ (Jenik et al., 2005), and A3-type cyclin (Yu et al., 2003) indicates the dependence of embryo patterning and morphogenesis on the correct execution of cell divisions. Also, lossof-function of HOBBIT (HBT), which encodes a homolog of the APC/C subunit CDC27 (Blilou et al., 2002), causes defects in hypophyseal cell specification and basal embryo cell division, perturbing root meristem formation (Willemsen et al., 1998). Recent investigation on Arabidopsis post-embryonic development indicates that moderate and high levels of CDKA;1 activity determine whether cells divide symmetrically or asymmetrically, respectively, and that CDKA;1 activity is conveyed via RBR1 and its control over cell cycle- and differentiationrelated genes (Weimer et al., 2012). Similar mechanisms connecting CDKs and RBR1 appear to operate during embryogenesis (Nowack et al., 2012), and several studies have shed light on the roles of the RBR/E2F pathway, CDKs, D-type cyclins, CKIs, as well as additional APC/C components, in developing Arabidopsis seeds, underscoring the importance of precise cell cycle control for embryonic patterning, cell proliferation, and endoreduplication.

\section{The role of D-type cyclins in embryogenesis}

Collins et al. (2012) carried out a comprehensive investigation of D-type cyclin expression and function in developing Arabidopsis seeds. Various D-type cyclin genes show distinct and overlapping tissue-specific expression patterns during seed development. Developmental progression characterized in loss-offunction mutants revealed that embryo development is slower in the triple D3-type cyclin mutant, but not in single and double mutant combinations, indicating that this cyclin subtype is necessary for normal development, with individual, partly redundant components. Ectopic CYCD3; 1 expression delays progression of embryonic development and causes atypical divisions in the hypophysis and suspensor. In contrast to CYCD3; 1, ectopic expression of CYCD7;1, a previously uncharacterized cyclin that is not expressed in wild-type seeds, induces cell proliferation and cell enlargement in the embryo (and endosperm), causing excessive growth and higher seed lethality. These results suggest that adequate control of spatiotemporal patterns of cell division, through the regulation of specific D-type cyclins and thus possibly their CDK complexes, is important for embryo patterning and growth.

\section{Roles of CDKs, the RBR pathway, and CKIs in embryogenesis}

A combinatorial analysis of mutants recently allowed functional dissection of five members of the ICK/KRP-type of CKIs during Arabidopsis seed development and revealed a link between ICK/KRPs, the RBR/E2F pathway and cell proliferation (Cheng etal., 2013). CDK activity gradually increased as individual ICK/KRP T-DNA insertion mutants were combined, indicating that ICK/KRPs act at least partially as dosage-dependent CDK inhibitors. Although single-gene mutants and most multiple-gene mutants have wild-type morphological phenotypes, the quadruple icklick2ick6ick7, and the quintuple ick1ick2ick5ick6ick7 mutants have a slightly altered leaf shape, suggesting some degree of redundancy among individual genes. The quintuple mutant has larger cotyledons, leaves, petals, and seeds than wild type. The ICK/KRP mutants generally have more numerous but smaller cells in all organs examined, and this phenotype is enhanced as the number of combined mutant genes is increased. The quintuple mutant displays extensive up-regulation of the E2F pathway via increased phosphorylation of RBR1, consistent with reduced inhibition of CDK complexes.

An additional connection between CDKs and RBR1 was provided by combinatorial analyses of their corresponding mutants (Nowack etal., 2012). Delayed development and drastically altered cell numbers and sizes are observed during embryogenesis in null $c d k a ; 1$ mutants (indicating that embryogenesis can adjust to variations of cell number and size), while loss of function of both CDKA;1 and B1-type CDKs leads to embryogenesis arrest. Because post-embryonic defects in cdka;1 mutants can be restored by rbrl mutations (Nowack et al., 2012), CDKA;1 most likely acts via the RBR/E2F pathway to control embryogenic cell proliferation. Arabidopsis DEL1 encodes an E2F-DP-like DNA binding protein that was previously shown to be mostly expressed in dividing cells and to inhibit endoreduplication (Vlieghe et al., 2005). A loss-offunction del1 mutant exhibits a small $(\sim 11 \%)$ but significant increase in seed size (Van Daele et al., 2012), although it was not determined whether this phenotype is due to stimulated endoreduplication. Collectively, these results suggest complex interactions among plant ICK/KRPs, which can function redundantly, but also in a dosage-dependent manner, to control the activity of CDK complexes, the RBR1/E2F pathway and cell proliferation.

\section{The influence of the APC/C in embryogenesis}

Functional characterization of genes encoding APC/C subunits and activators during embryogenesis revealed roles in cell-type specification and morphogenesis, in addition to cell division and endoreduplication. Mutations in both APC4 (Wang et al., 2012) 
and APC1 subunits (Wang et al., 2013) cause defective gametogenesis and developmental arrest during embryogenesis, which seem to be associated with accumulation of B-type cyclin and altered auxin distribution. SAMBA encodes a conserved plantspecific protein that binds to and potentially regulates the APC/C (Eloy et al., 2012). SAMBA expression is high during embryogenesis and, to a lesser extent, early post-embryonic development. Loss-of-function samba mutants have defective male gametogenesis and enlarged shoot and root apical meristems that result in the production of larger seeds, embryos, leaves, and roots. Increased organ size in samba mutants could be attributed to a larger number of more highly endoreduplicated cells, rather than to larger cells. SAMBA binds an A2-type cyclin, which is stabilized in samba mutants during early development. Thus, SAMBA negatively regulates cell proliferation at least partially by targeting A2-type cyclins for proteolysis via the APC/C.

In conclusion, precise cell cycle regulation, both spatially and temporally, is critical for embryogenesis and plant reproduction. The core cell cycle regulators CDKs, cyclins, RBR1, ICK/KRPs, and the APC/C seem to play concerted roles and thus affect asymmetrical cell divisions, cell proliferation and endoreduplication during embryogenesis.

\section{ENDOSPERM}

\section{Patterns of endosperm development}

The endosperm functions in nourishing the sporophyte during embryogenesis and controlling germination and, mostly limited to monocots, also during early post-embryonic development. However, it also plays important roles in other aspects of seed development, including epigenetic regulation, coordination of cell patterning and proliferation, signaling among the major seed structures and control of seed size (Berger et al., 2006; Sabelli and Larkins, 2009b; Nowack et al., 2010; Fiume and Fletcher, 2012; Costa et al., 2014). The different cell cycle types occurring during the development of the persistent endosperm in grasses have mostly been investigated in traditional biological models and valued crop species, such as maize and rice (Oryza sativa).

The nuclear type of endosperm development is the most frequently encountered pattern among Angiosperms, and with regard to its early stages up to cellularization, is highly conserved in monocots and dicots (Olsen, 2004; Sabelli and Larkins, 2009b; Becraft and Gutierrez-Marcos, 2012). In this developmental type, the primary endosperm nucleus and its derivatives undergo acytokinetic mitosis iteratively, resulting in a syncytium that can comprise up to thousands of nuclei that are initially distributed around the central vacuole of the central cell (Olsen, 2004). Anticlinal cell wall deposition, forming alveoli encasing individual nuclei, creates the first endosperm cell layer, and reiteration of anticlinal cell wall deposition, alveolation, periclinal cell wall formation and periclinal cell division results in centripetal generation of additional cell layers, gradually replacing the space occupied by the central vacuole with cells. Cellularization is typically completed within three to six days after pollination (DAP) in cereals and by the torpedo stage in Arabidopsis. In the following developmental stage, mitotic divisions coupled to cytokinesis result in cell proliferation, thus producing most of the endosperm cells. Past the cell proliferation stage, in nonendospermic species, such as Arabidopsis, the endosperm is absorbed by the rapidly developing embryo and is limited to a single or few cell layers at seed maturity. In contrast, in endospermic species, the endosperm is persistent and its development progresses through relatively conserved stages, comprising a period of cell enlargement typically associated with endoreduplication, followed by maturation involving programmed cell death (PCD) of specific cell types, dehydration, and dormancy. The roles played by core cell cycle regulators in the different cell cycles of cereal endosperm development are discussed in the following sections and summarized in Figure 3.

\section{Maize endosperm development: an overview}

Endosperm development in maize (and related cereals) follows the general monocot developmental pattern described earlier (Sabelli and Larkins, 2009b). Starting around three DAP, as the syncytium is cellularized, endosperm growth is mostly attained by an increase in cell number through mitotic cell divisions, which peak at eight to 10 DAP (Kiesselbach, 1949; Kowles and Phillips, 1985; Lur and Setter, 1993). Initiating in the endosperm central regions, also around eight to 10 DAP and then extending centrifugally, cells gradually and asynchronously cease mitotic cell divisions and switch to endoreduplication. As a result, the nuclei of many central endosperm cells reach high DNA content levels (some in excess of 200C; $\mathrm{C}=$ DNA content of haploid nuclei) and contain multiple, apparently uniform, copies of chromosomes (Bauer and Birchler, 2006). In agreement with the high correlation between ploidy level and cell size observed in numerous cell types and organisms, the spatiotemporal pattern of mitosis-to-endoreduplication switch in the maize endosperm creates a gradient of nuclear ploidy and cell size. Small non- or under-endoreduplicated cells are located mostly at the peripheral aleurone and sub-aleurone layers, as opposed to the increasingly large and endoreduplicated inner starchy endosperm cells. By 16 DAP, the expanded endoreduplicated cells account for most of the endosperm volume (Vilhar et al., 2002) and as many as $75 \%$ of its cells can become endoreduplicated at later developmental stages (Dilkes et al., 2002). Starchy endosperm cells typically display concomitant accumulation of starch and proteins with endoreduplication, which has long suggested a causal relationship between these processes (Larkins et al., 2001; Kowles, 2009; Sabelli and Larkins, 2009a,b; Sabelli, 2012b). Starchy endosperm cells subsequently undergo PCD (reviewed by Young and Gallie, 2000; Sabelli, 2012a), and the peripheral aleurone layer persists as the only living tissue past seed desiccation.

\section{The contrasting endosperm development in Brachypodium distachyon and other model cereals}

In comparison with maize, rice, and other major cereals, initial analyses of seed development in the emerging grass model, Brachypodium distachyon, have revealed important differences with respect to cell cycle control and its possible relationship with storage compound accumulation (Guillon et al., 2012; Trafford et al., 2013). In contrast to its related species, barley (Hordeum vulgare), Brachypodium endosperm displays reduced cell proliferation and enlargement. Also, the expression of a B1-type CDK and 


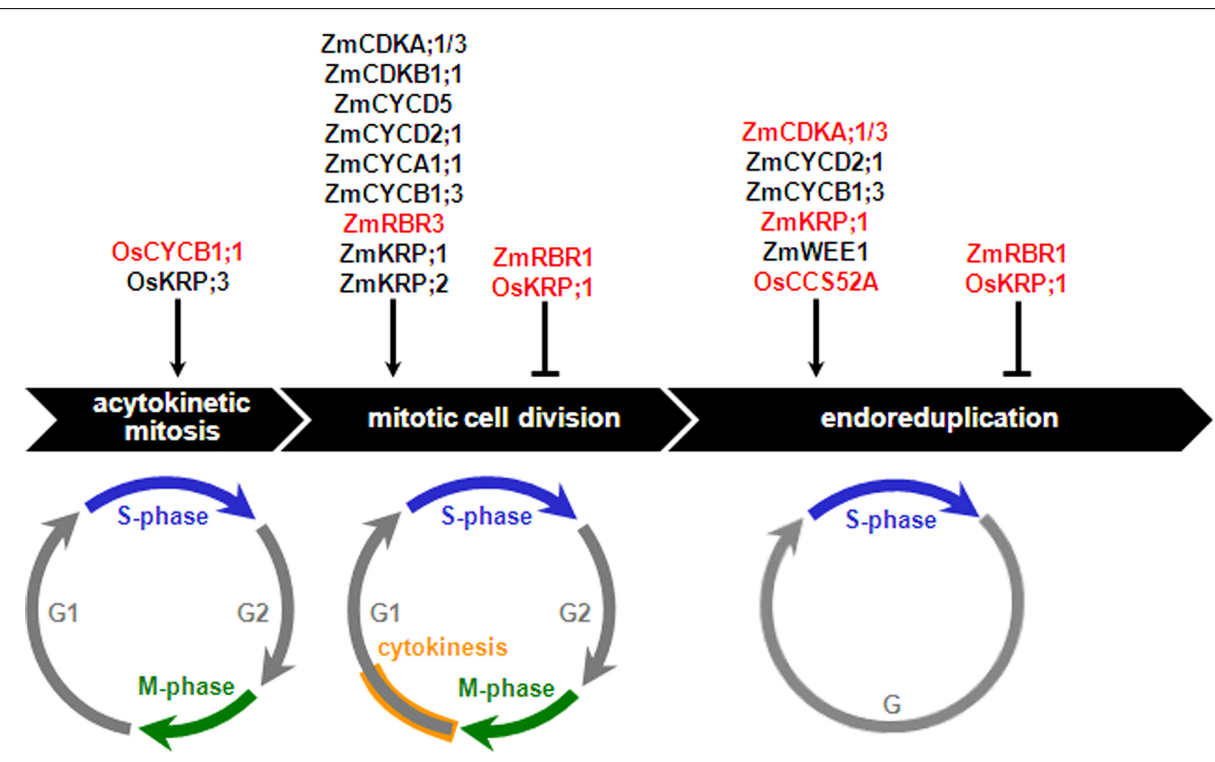

FIGURE 3 | Effects of core cell cycle regulators on the cereal endosperm cell cycles. Core cell cycle regulators that positively or negatively regulate proliferative (acytokinetic mitosis and mitotic cell division) and endoreduplication cycles are shown. Net stimulatory or inhibitory effects are assigned as a function of cell proliferation- and ploidy-related phenotypes observed in mutant or transgenic analyses carried out either in planta or plant cell cultures (red-colored fonts) or inferred from a combination of expression analyses and biochemical assays (black-colored fonts), as discussed in the text. Os, Oryza sativa; Zm, Zea mays. an A3-type cyclin is reduced, in agreement with a withdrawal from a mitotic cell cycle program, but $>6 \mathrm{C}$ nuclei are absent, indicating no occurrence of endoreduplication. Along with these differences, Brachypodium endosperm cells exhibits limited starch deposition and thickened cell walls, the cell wall polysaccharide, $\beta$-glucan, representing the main seed storage carbohydrate. Accordingly, the expression of genes involved with starch biosynthesis is reduced. Thus, an interpretation of the contrasting endosperm developmental patterns in Brachypodium and other cereals is that starch accumulation drives endosperm cell enlargement (Trafford et al., 2013) and, consequently, high nuclear ploidy levels are correlated with large cell sizes.

\section{The importance of early nuclear and cell proliferation activities for endosperm development}

Regulation of the syncytium-to-cellularization transition seems to be key for endosperm development and seed growth. Rice THOUSAND-GRAIN WEIGHT 6 (TGW6), which encodes an indole-3-acetic acid (IAA)-glucose hydrolase, appears to stimulate, by elevating IAA levels, the expression of CYCB2;2 and E2F1 during the first three days after fertilization; it also stimulates premature cellularization of the syncytium and reduces endosperm final cell number, grain length, and weight (Ishimaru et al., 2013). In addition, suppressing the expression of rice CYCB1;1 results in delayed endosperm cellularization and seeds containing only an enlarged embryo at maturity (Guo etal., 2010). Heat stress affects rice endosperm cellularization by interfering with the expression of the epigenetic regulator FERTILIZATION-INDEPENDENT ENDOSPERM 1 of the Polycomb Repressive Complex 2 (PRC2), thus reducing seed size (Folsom et al., 2014). In Arabidopsis, over-expression of SHORT HYPOCOTYL UNDER BLUE 1 (SHB1) promotes early endosperm nuclear proliferation, a delay in cellularization, enlarged chalazal endosperm, and enhanced proliferation and expansion of embryo cells, leading consequently to increased seed size (Zhou etal., 2009). It is possible that these effects are mediated by members of the HAIKU pathway, which function downstream of SHB1 to promote syncytial endosperm and seed growth via epigenetic control of cytokinin signaling (Li et al., 2013).

The rate and duration of proliferative cell cycles seem to also play an important role in maize seed size. Recently, Sekhon et al. (2014) examined transcriptional and developmental changes during seed development of maize populations that were selected for large and small seed sizes (termed KLS30 and KSS30, respectively). KLS30 seeds are more than fourfold heavier and twofold larger than KSS30 seeds and contain proportionally larger endosperms. Metabolite and genome-wide expression analyses indicated that, compared to KLS30 seeds, the linear phase of the grain filling (phase II) in KSS30 seeds initiates earlier, but it also occurs at slower rates and terminates earlier. Notably, KLS30 endosperms, relative to their KSS30 counterparts, display upregulated sucrose metabolism and expression of the cell wall invertase INCW2 (encoded by the MINIATURE 1 gene), which is required for normal endosperm cell proliferation and expansion (Vilhar et al., 2002; Chourey et al., 2006). KLS30 endosperms also exhibit higher expression at 12-18 DAP of several genes encoding D- and B-type cyclins and APC/C subunits. Although cell number, size, and nuclear ploidy were not determined in KLS30 and KSS30 endosperms, these gene expression profiles suggest higher mitotic activity in the former. The balance between cell proliferation and endoreduplication activities as a factor influencing 
endosperm and seed sizes is also supported by the analyses of multiple small-seeded popcorn inbred lines in comparison to typically large-seeded dent inbred lines (Dilkes et al., 2002; Coelho et al., 2007). Popcorn lines revealed higher endosperm ploidy levels from as early as 13 DAP in comparison to dent inbred lines. This difference could be attributed to an earlier transition between the cell division to endoreduplication stages, and/or higher rates of endoreduplication in popcorn lines. The importance of correct timing for cessation of cell proliferation and commencement of cell enlargement as an underlying factor for growth has been documented (reviewed by Powell and Lenhard, 2012). Collectively, these studies suggest a causal relationship between increased periods and/or rates of cell proliferation with larger endosperms (and, consequently, larger seeds), by establishing a stronger-sink tissue, one possessing more numerous cells that subsequently enlarge and accumulate larger amounts of storage compounds.

\section{SEED COAT DEVELOPMENT, CELL CYCLE CONTROL, AND EPIGENETIC CONTROL OF SEED DEVELOPMENT}

In most Angiosperms, the two ovule integuments that enclose the nucellus differentiate into the seed coat following fertilization, and develop through stages of cell division, cell elongation, differentiation, and PCD in coordination with embryo and endosperm development (Haughn and Chaudhury, 2005). Investigation of Arabidopsis seed coat development revealed the existence of complex communication and interaction between these seed structures and that their underlying cell proliferation and enlargement are major determinants of seed size (reviewed by Nowack et al., 2010). Impairing the elongation of integument cells via the transparent testa glabra 2 (ttg2) mutation reduces endosperm and seed growth (Garcia et al., 2005). megaintegumentalauxinresponse factor 2 (mnt/arf2) mutants exhibit more numerous integument cells and enlarged seeds and embryos compared to wild type (Schruff et al., 2006). Premature syncytium cellularization reduces endosperm growth and integument cell elongation in haiku (iku) mutants (Garcia etal., 2005), whereas delayed cellularization and extended endosperm cell proliferation is associated with integument cell elongation in the enlarged seeds of apetala 2 (ap2) mutants (Ohto et al., 2009). The enhanced cell proliferation in mnt/arf2 and ap2 mutants seems to be associated with increased expression of D3- and B1-type cyclins (Schruff et al., 2006; Ohto et al., 2009), indicating that the corresponding transcription factors repress cell divisions through a pathway that involves down-regulation of these core cell cycle regulators.

Epigenetic mechanisms are particularly important for integrating growth and development of the seed coat, embryo, and endosperm. Particularly among core cell cycle regulators, RBR1 is involved in gametophyte cell differentiation and endosperm nuclear proliferation along with epigenetic regulators such as PRC2 and DNA METHYLTRANSFERASE 1 (Ebel et al., 2004; Ingouff etal., 2006; Johnston et al., 2008; Jullien et al., 2008). rbr1 mutants display fertilization-independent endosperm development, reduced cell proliferation in the ovule integuments prior to fertilization and impaired differentiation of the seed coat (Ebel et al., 2004; Ingouff et al., 2006).
In conclusion, there appears to be extensive crosstalk and coordination, in which epigenetic control and RBR1 play significant roles, between cell cycle activity in the developing seed coat and inner seed structures, such as the embryo and endosperm. These mechanisms could modify both signaling and mechanical constrains imposed by maternal tissues on developing seed structures, and consequently could control seed size (Haughn and Chaudhury, 2005).

\section{THE ROLE OF CORE CELL CYCLE REGULATORS IN THE CEREAL ENDOSPERM: THE MAIZE PROTOTYPE AND RELATED EXAMPLES CONTROL OF ENDOREDUPLICATION IN ENDOSPERM}

The mechanisms that control the transition from the mitotic cell cycle into endoreduplication and its progression in various cell types and species have been recently reviewed in detail (Edgar et al., 2014; Sabelli, 2014). Among plant core cell cycle regulators, certain $\mathrm{CDK} /$ cyclin complexes, CKIs, APC/C activators and the RBR/E2F pathway have been functionally linked to the onset and/or rates of endoreduplication cycles. Although these cell cycle regulators are widely conserved across higher eukaryotes and appear to be recurrently deployed to produce cell cycle modifications that result in endoreduplication, their individual contributions may be species- and cell-typespecific (Roodbarkelari et al., 2010; Edgar et al., 2014). In maize endosperm, induced S-phase CDK activity and inhibited Mphase CDK activity were proposed to cause endoreduplication cycles (Grafi and Larkins, 1995). In support of this model, endoreduplication is inhibited and stimulated, respectively, by over-expression of a catalytically inactive, dominant-negative form of CDKA; 1 (Leiva-Neto et al., 2004) and by decreased RBR1 activity and consequent up-regulation of E2F/DP-dependent gene expression (Sabelli et al., 2013). In addition, developing maize endosperm exhibits the contrasting expression of different CKIs (Coelho et al., 2005) and functionally distinct RBR homologs of the RBR1 and RBR3 types (Grafi et al., 1996; Sabelli et al., 2005, 2009, 2013). Endosperm endoreduplication particularly correlates with the potential inhibitory phosphorylation of CDK subunits by a WEE1 homolog (Sun etal., 1999a), differential cyclin expression (Sun etal., 1999b; Dante etal., 2014) and apparent down-regulation of UPS-mediated proteolysis of members of various cyclin types, including potential mitotic cyclins (Dante et al., 2014).

\section{CKIs}

ICK/KRP-type CKIs appear to have variable roles in different cell cycle types during cereal endosperm development. KRP;1 is expressed at nearly constant levels in 7-21 DAP endosperm, while KRP; 2 protein levels decline during this period, suggesting a more positive role in endoreduplicating cells for KRP;1 than KRP;2, which in contrast could be preferentially involved with regulation of the mitotic cell cycle or its transition into the endoreduplication cycle (Coelho et al., 2005). Biochemical assays showed KRP; 1 activity corresponds partly to a CDK inhibitory activity existing in endoreduplicating endosperm (Grafi and Larkins, 1995). KRP;1 and KRP;2 are able to partially inhibit 
the complex CDK fraction that binds $\mathrm{p} 13^{\text {suc } 1}$, and they specifically inhibit the CDK activity associated with A1- and D5-type cyclins, but not that associated with CYCB1;3 (Coelho et al., 2005). Overexpression of KRP; 1 along with the wheat dwarf virus RepA protein, which antagonizes RBR1 (Grafi etal., 1996; Xie et al., 1996; Gordon-Kamm et al., 2002; Sabelli et al., 2005, 2009), causes ectopic endoreduplication in cultured, proliferating maize cells, indicating that coupling the stimulation of G1/S transition to the inhibition of certain CDK complexes is sufficient for endoreduplication onset in otherwise dividing cells (Coelho et al., 2005).

Expression and functional analyses in planta revealed that KRPs impact rice endosperm development. KRP;1 RNA is preferentially expressed at the mitosis-to-endoreduplication transition in wildtype rice plants, and its over-expression results in decreased kernel weight and filling rate, in addition to perturbed production and lower ploidy levels of endosperm cells (Barrôco et al., 2006). In contrast, KRP;3 RNA is most highly expressed in the syncytial endosperm, but its level declines subsequently in the cellularized endosperm, suggesting a specific function in the syncytial cell cycle or during the transition to cellularization (Mizutani et al., 2010).

\section{THE CDK AND RBR PATHWAYS}

Recently, Sabelli et al. (2013) showed that RBR1 controls multiple molecular and cellular aspects of maize endosperm development. RBR1 down-regulation via RNAi in endosperm cells results in enhanced expression of RBR3-type, MCM2-7, and PCNA genes. Mitotic and endoreduplication cell cycles are both stimulated by the alleviated inhibition of RBR1 on the G1/S transition, which causes RBR1-RNAi endosperm to have 58\% more cells and $\sim 70 \%$ more DNA than its wild type counterpart by 19 DAP. However, this creates a surprising reduction in cell and nuclear sizes, in spite of increased endoreduplication, thus ruling out a causal and direct relationship between these processes, at least in the specific context of RBR1 down-regulation. Larger cell numbers and higher ploidy levels together cause a $43 \%$ increase in DNA content in mature endosperm upon RBR1 down-regulation, although no measurably altered storage protein content or kernel weight (a proxy for starch accumulation) were observed. Genetic interaction analysis of RBR1 and CDKA;1 (Leiva-Neto et al., 2004), down-regulated individually or in combination, indicated that CDKA; 1 requires RBR1 for controlling endoreduplication, but conversely RBR1 represses downstream target genes independently from CDKA;1. These observations suggest distinct RBR1 activities at controlling endoreduplication, in which CDKA;1 probably participates via its inhibitory phosphorylation of RBR1, and at repressing E2F-dependent gene expression in a CDKA;1-independent manner. RBR1 down-regulated endosperm exhibits levels of $\mathrm{p} 13^{\text {suc } 1}$-adsorbed CDK activity similar to those of wild-type endosperm even in the presence of dominantnegative CDKA;1, indicating that various CDK complexes and RBR1 are negatively and reciprocally regulated, and implying that CDKs other than CDKA;1 participate in cell cycle stimulation upon RBR1 down-regulation (Leiva-Neto et al., 2004; Sabelli etal., 2013; Dante etal., 2014). Thus, perturbing RBR1 function revealed its key roles in integrating various processes in maize endosperm, but this did not translate in altered seed size and weight, suggesting the presence of a higher order, homeostatic regulation of endosperm development (discussed in next section).

The stimulation of CDK activity in down-regulated RBR1 maize endosperm prompts the question of the identity of CDKs, besides CKDA;1, controlling cell division and endoreduplication cycles (Sabelli et al., 2013). The identification and expression of different CDKs expressed in maize endosperm were reported recently (Dante et al., 2014). Previously uncharacterized CDKs of the A-type and B1-types, termed, respectively, CDKA;3 and CDKB1;1, were found to be expressed in endosperm. Protein levels of A-type CDKs are nearly constant throughout endosperm development, whereas expression of CDKB1;1 becomes markedly reduced during the transition into the endoreduplication stage and is stimulated upon RBR1 down-regulation. These observations are in agreement with the role of A-type CDKs in both mitotic and endoreduplication cell cycles and that of B1-type CDKs specifically in the mitotic cell cycle established in other species. Similar expression patterns, cyclin binding properties, and maintenance of nearly wild-type levels of CDK activity upon combined down-regulation of RBR 1 and CDKA; 1 collectively indicate that CDKA;1 and CDKA;3 are partially redundant or function coordinately (Sabelli et al., 2013; Dante et al., 2014). RBR1 downregulated endosperm possesses more numerous cells and also exhibits higher ploidy levels, indicating that both cell division and endoreduplication are stimulated in distinct spatiotemporal patterns (Sabelli et al., 2013). These results suggest some redundancy among A-type CDKs and a specialized role for CDKB1;1 in positively regulating cell division during maize endosperm development (Leiva-Neto et al., 2004; Sabelli et al., 2013; Dante et al., 2014). Consistent with this interpretation, Arabidopsis possesses a single A-type CDK, and its B1-type CDKs can drive progression through cell division, but not endoreduplication cycles, in the absence of CDKA;1 and RBR1 (Nowack et al., 2012).

\section{CYCLIN/CDK COMPLEXES}

The spatiotemporal expression of A-, B-, and D-type cyclins and their associated kinase activities in developing maize endosperm were recently investigated (Dante et al., 2014). Two main transcript expression patterns are apparent, one characterized by rapidly declining RNA levels with the onset of endoreduplication (A- and B-type cyclins), and the other with nearly constant RNA levels throughout endosperm development (D-type cyclins). However, these patterns are not consistent with those at the protein level, as shown by a discrepancy between declining $C Y C B 1 ; 3$ RNA in endoreduplicating endosperm but sustained levels of the encoded protein. While CYCB1;3 and CYCD2;1 proteins are localized to both the cytoplasm and nucleus of cells throughout the endosperm, CYCD5 protein is localized solely in the cytoplasm of peripheral cell layers. CDK activity associated with CYCA1 is tightly associated with cell division, while CYCB1;3-, CYCD2;1-, and CYCD5-associated CDK activities are highest at the transition from cell division to endoreduplication. These patterns together suggest roles for CYCA1 and CYCD5 in the cell division cycle, while CYCB1;3 and CYCD2;1 could participate in both cell division and endoreduplication. In particular, the switch to an endoreduplication program is marked 
by a drastic reduction in kinase activity associated with CYCA1. A-, B-, and D-type cyclins are more resistant to proteasomedependent degradation in endoreduplicating compared to mitotic endosperm, which potentially contributes to the sustained levels of proteins, particularly CYCB1;3, in endoreduplicating cells. Consequently, the mitosis-to-endoreduplication transition and the accompanying cell enlargement typical of starchy endosperm cells are possibly associated with cell cycle modifications created by reduced proteasome-dependent proteolysis of several types of cyclins and, potentially, that of additional core cell cycle regulators (Dante et al., 2014).

\section{UPS-MEDIATED PROTEOLYSIS}

Functional and expression analyses in rice revealed roles for $\mathrm{APC} / \mathrm{C}$ activators that seem in part distinct from those of their homologs in dicots. Reduced expression of CELL CYCLE SWITCH 52A (OsCCS52A), a homolog of the APC/C activating subunit, results in smaller seeds and, despite reduced nuclear and cell size of endosperm cells, only modest reduction in their ploidy levels (Su'udi et al., 2012b). Also, reduced expression of the related OsCCS52B protein negatively impacts seed and cell sizes, but has no impact on endoreduplication (Su'udi et al., 2012a). Thus, collectively, OsCCS52A and B seem to play rather minor roles in rice endosperm endoreduplication, but have important roles in controlling cell and seed sizes. Although plant CCS52 homologs are known to promote proteolysis of A- and B-type cyclins and endoreduplication (reviewed by Heyman and De Veylder, 2012), the targets and mechanisms by which OsCCS52A and B control cell and seed sizes remain unknown. Some unidentified cyclins are presumably targeted by OsCCS52A and B, but the apparent downregulation of UPS-mediated cyclin degradation and its contribution to sustained CYCB1;3 expression in endoreduplicating maize endosperm cells (Dante et al., 2014) further suggests that CCS52 homologs have a more significant role in cyclin proteolysis in mitotic as opposed to endoreduplicating endosperm. Also, these observations are consistent with others made in dicot model species, underscoring that various plant cell cycle regulators are targeted to UPS-mediated degradation by E3 ubiquitin ligases in cell-type- and cell cycle-type-dependent manners (Roodbarkelari etal., 2010; Heyman and De Veylder, 2012). Thus, dissecting the specific roles of E3 ubiquitin ligases and the UPS at large in governing various aspects of endosperm development, including cell cycle control, merits further investigation.

Besides the apparently reduced UPS activity in endoreduplicating compared to mitotic endosperm, translational regulation may also be responsible, at least in part, for sustained CYCB1;3 protein levels despite drastically reduced amounts of its RNA, as cyclin expression is known to be regulated at this level. In addition, many levels of gene expression regulation operate extensively during seed development, as a comparative analysis of the developing maize seed transcriptome and proteome revealed large discrepancies between cognate RNA and protein levels (Walley et al., 2013). Possible underlying mechanisms include differential stability of RNA and protein pairs, transport of proteins between tissues and out-of-phase circadian accumulation of corresponding RNAs and proteins (Walley et al., 2013). Thus, the expression of CYCB1;3 and other core cell cycle regulators in different seed structures may be subject to complex regulation.

\section{WHAT IS THE ROLE OF ENDOREDUPLICATION? EVIDENCE FROM THE MAIZE ENDOSPERM}

Proliferative cell cycles are ultimately responsible for establishing the number of cells in a tissue, organ or body and, together with cell enlargement, determine their overall size. Although increased tissue/organ/body size resulting from stimulated cell proliferation has been documented in plants, typically the proliferation and enlargement of cells are inversely correlated, as more numerous cells are compensated for at the tissue/organ level by reduced cell size, essentially resulting in no overall differences (reviewed by John and Qi, 2008; Powell and Lenhard, 2012; Sabelli, 2014). A long-standing debate persists that opposes the "cell-based" or "cellular theory" (whereby cell proliferation and enlargement drive tissue/organ/body growth in a cell-autonomous manner) and the "organismal theory" (cell proliferation and enlargement follow a higher-order, supra-cellular program; Beemster et al., 2006; John and Qi, 2008; Sabelli, 2014).

While the impact of cell proliferation on tissue/organ/body size can be easily appreciated, that of endoreduplication is more controversial. Endoreduplication displays remarkable coincidence with cell enlargement in numerous cell types associated with different specialized functions. In an emerging and unifying view, endoreduplication facilitates cell expansion, growth, and accompanies differentiation in multiple cell types in which the occurrence of cell division could impair their function (Edgar etal., 2014). Among plant cells, the cellular functional specializations and attributes commonly associated with cell enlargement and endoreduplication include ability for rapid cell elongation (e.g., hypocotyl cells), branched cell morphology (e.g., trichomes), nutrient storage (e.g., cotyledons and endosperm of seeds and pericarp of fleshy fruits), hosting endosymbiotic bacteria (e.g., nodule giant cells) and interaction with pathogens and parasites (e.g., giant cells in galls and feeding sites). Some functions of endoreduplication in plant cells are only beginning to be elucidated (reviewed by John and Qi, 2008; Chevalier et al., 2011,2013; De Veylder et al., 2011; Edgar et al., 2014; Sabelli, 2014). Recently, the contribution of endoreduplication to cell morphogenesis and cell identity maintenance (Bramsiepe et al., 2010), as well as regulation of gene expression and karyoplasmic homeostasis (Bourdon etal., 2012) were investigated. Bramsiepe et al. (2010) reported that, upon targeted reduction of endoreduplication levels by modification of core cell cycle gene expression, Arabidopsis trichome number is reduced due to dedifferentiation and resumption of mitosis by these cells. Conversely, promoting endoreduplication causes restoration of trichome cell identity, which revealed a role for endoreduplication in determining trichome cell fate. In endoreduplicated cells of the tomato pericarp, the nuclear surface has extensive grooves that are filled with mitochondria, thus allowing fairly constant nuclear surface/volume ratios, suggesting the existence of high ATP demand by nuclear processes 
(Bourdon et al., 2012). Accordingly, rRNA and mRNA transcription in individual nuclei is positively correlated with ploidy levels.

In the terminally differentiated starchy cells of maize endosperm, endoreduplication can be viewed as a mechanism that supports increased gene expression and the enhanced metabolic activity associated with cell enlargement and massive accumulation of starch and storage protein (Larkins et al., 2001; Sabelli and Larkins, 2009a; Sabelli, 2014). However, modification of endosperm endoreduplication, by perturbing the function of core cell cycle regulators, has challenged some aspects of this paradigm (Leiva-Neto et al., 2004; Sabelli et al., 2013). Similar to maize kernels in which the expression of a dominant-negative CDKA;1 reduces endoreduplication (Leiva-Neto et al., 2004), the size, weight, and morphology of RBR1 down-regulated kernels are essentially identical to their wild-type counterparts (Sabelli et al., 2013). Thus, evidence from modification of maize endosperm endoreduplication suggests this cell cycle does not contribute to metabolic and growth processes, at least at a whole-tissue level.

Surprisingly, RBR1 down-regulation in endosperm also results in coordinated reduction in cell and nuclear sizes (Sabelli et al., 2013). This indicates a role for RBR1 in coupling DNA content to nuclear and cell sizes. Importantly, these results invoke the existence of a causal relationship between nuclear and cell sizes in endosperm cells, which is not affected by perturbing RBR1 function, in support of the general karyoplasmic ratio theory. In addition, the observation of a larger number of smaller cells in RBR1 down-regulated endosperm seems to agree with the organismal theory of development. Consequently, one interpretation of the effects of RBR1 down-regulation in maize endosperm is that suppression of RBR1 function leads to enhanced cell proliferation, which results in a larger number of cells that, nonetheless, undergo less pronounced enlargement imposed by supra-cellular control of tissue size. Nuclear sizes are adjusted to the sizes of respective cells, regardless of their higher ploidy levels, which are achieved via enhanced endoreduplication. In RBR1 down-regulated endosperm, both the uncoupling of ploidy levels from cell and nuclear size and the reduced storage protein gene expression per unit of nuclear DNA possibly arise from increased DNA methylation and chromatin condensation (Sabelli et al., 2013), in a fashion similar to Arabidopsis cotyledon cells (van Zanten et al., 2011). Importantly, additional chromatin produced by enhanced endoreduplication in RBR1 down-regulated endosperm seems to be less transcriptionally active (Sabelli et al., 2013), providing latent transcriptional capacity in case cell enlargement is resumed or continued. Consequently, at the individual cell level, endoreduplication in the endosperm could function in the adjustment of nuclear size to cell size (thus preserving the karyoplasmic ratio) through a process influencing chromatin condensation states and transcription. This view seems to be supported by evidence from other model systems (Wu et al., 2010; Bourdon et al., 2012).

A deeper understanding of the role endoreduplication plays in endosperm development may require genetic analyses of this cell cycle by perturbing individual genes other than those encoding core cell cycle regulators, whose possible functions at coupling endoreduplication to cellular outputs may produce confounding results. The existence of compensatory mechanisms mediating tissue homeostasis may also require approaches based on a suite of technologies such as transmission electron and fluorescence microscopy, immunohistochemistry, DNA and RNA in situ hybridization, in vitro tissue culture and flow cytometry/fluorescence-activated nuclear sorting to unmask cell-autonomous effects (Gruis et al., 2006; Bourdon et al., 2012).

\section{CONCLUDING REMARKS}

Acytokinetic mitosis, symmetric and asymmetric cell division, and cell enlargement greatly impact seed growth and development. During embryogenesis, correct execution of cell division is required for patterning and morphogenesis. Both the rates of proliferative and endoreduplication cell cycles (the latter of which being typically integral to cell enlargement and differentiation in storage compartments) and the timing of the developmental transitions between these cell cycles influence the final size of seed structures and ultimately that of the whole seed. In Arabidopsis, a pivotal role of its only RBR member, RBR1, in asymmetric cell divisions, gametogenesis and embryogenesis has been revealed, while in the developing cereal endosperm the RBR1 homolog is central to the control of cell proliferation and endoreduplication cycles and nuclear and cell sizes, underscoring the importance of this family of core cell cycle regulators for plant reproduction and development. Differential expansion of families of key cell cycle genes in various plant species seems to allow the establishment of both functional redundancy and specialization, creating complex cell cycle regulatory networks. Genome-wide analyses and functional gene characterization studies have recently begun to reveal potentially important differences in cell cycle control between dicots and monocots. These differences are evident from genetic analyses of members of the RBR family, whose increased complexity in grass species can allow functional diversification, as exemplified by RBR1 and RBR3. The APC/C and cyclin proteolysis appear to play less prominent roles in the control of cereal endosperm endoreduplication than in dicot root nodules, trichomes, and pericarp. More investigation is needed to unravel the functions of different cell cycle types and their underlying regulatory pathways in endosperm growth, development, and function.

\section{ACKNOWLEDGMENTS}

Research on cell cycle regulation in the Larkins laboratory was supported by grants from the Department of Energy (DEFGO3-95ER20183 and DE-96ER20242) and Pioneer Hi-Bred International Inc. Ricardo A. Dante was supported by a graduate scholarship from the Conselho Nacional de Desenvolvimento Científico e Tecnológico of Brazil.

\section{REFERENCES}

Barrôco, R. M., Peres, A., Droual, A. M., De Veylder, L., Nguyen Le, S. L., De Wolf, J., et al. (2006). The cyclin-dependent kinase inhibitor Orysa;KRP1 plays an important role in seed development of rice. Plant Physiol. 142, 1053-1064. doi: 10.1104/pp.106.087056

Bauer, M. J., and Birchler, J. A. (2006). Organization of endoreduplicated chromosomes in the endosperm of Zea mays L. Chromosoma 115, 383-394. doi: $10.1007 / \mathrm{s} 00412-006-0068-2$ 
Becraft, P. W., and Gutierrez-Marcos, J. (2012). Endosperm development: dynamic processes and cellular innovations underlying sibling altruism. Wiley Interdiscip. Rev. Dev. Biol. 1, 579-593. doi: 10.1002/wdev.31

Beemster, G. T., Vercruysse, S., De Veylder, L., Kuiper, M., and Inze, D. (2006). The Arabidopsis leaf as a model system for investigating the role of cell cycle regulation in organ growth. J. Plant Res. 119, 43-50. doi: 10.1007/s10265-005-0234-2

Berger, F., Grini, P. E., and Schnittger, A. (2006). Endosperm: an integrator of seed growth and development. Curr. Opin. Plant Biol. 9, 664-670. doi: 10.1016/j.pbi.2006.09.015

Blilou, I., Frugier, F., Folmer, S., Serralbo, O., Willemsen, V., Wolkenfelt, H., et al. (2002). The Arabidopsis HOBBIT gene encodes a CDC27 homolog that links the plant cell cycle to progression of cell differentiation. Genes Dev. 16, 2566-2575. doi: $10.1101 /$ gad.237302

Bourdon, M., Pirrello, J., Cheniclet, C., Coriton, O., Bourge, M., Brown, S., et al. (2012). Evidence for karyoplasmic homeostasis during endoreduplication and a ploidy-dependent increase in gene transcription during tomato fruit growth. Development 139, 3817-3826. doi: 10.1242/dev.084053

Bramsiepe, J., Wester, K., Weinl, C., Roodbarkelari, F., Kasili, R., Larkin, J. C., et al. (2010). Endoreplication controls cell fate maintenance. PLoS Genet. 6:e1000996 doi: 10.1371/journal.pgen.1000996

Cebolla, A., Vinardell, J. M., Kiss, E., Olah, B., Roudier, F., Kondorosi, A., et al. (1999). The mitotic inhibitor ccs52 is required for endoreduplication and ploidy-dependent cell enlargement in plants. EMBO J. 18, 4476-4484. doi: 10.1093/emboj/18.16.4476

Cheng, Y., Cao, L., Wang, S., Li, Y., Shi, X., Liu, H., et al. (2013). Downregulation of multiple CDK inhibitor ICK/KRP genes upregulates the E2F pathway and increases cell proliferation, and organ and seed sizes in Arabidopsis. Plant J. 75, 642-655. doi: 10.1111/tpj.12228

Chevalier, C., Bourdon, M., Pirrello, J., Cheniclet, C., Gévaudant, F., and Frangne, N. (2013). Endoreduplication and fruit growth in tomato: evidence in favour of the karyoplasmic ratio theory. J. Exp. Bot. 65, 2731-2746. doi: 10.1093/jxb/ert366

Chevalier, C., Nafati, M., Mathieu-Rivet, E., Bourdon, M., Frangne, N., Cheniclet, C., etal. (2011). Elucidating the functional role of endoreduplication in tomato fruit development. Ann. Bot. 107, 1159-1169. doi: 10.1093/ aob/mcq257

Chourey, P. S., Jain, M., Li, Q. B., and Carlson, S. J. (2006). Genetic control of cell wall invertases in developing endosperm of maize. Planta 223, 159-167. doi 10.1007/s00425-005-0039-5

Coelho, C. M., Dante, R. A., Sabelli, P. A., Sun, Y., Dilkes, B. P., Gordon-Kamm, W. J., et al. (2005). Cyclin-dependent kinase inhibitors in maize endosperm and their potential role in endoreduplication. Plant Physiol. 138, 2323-2336. doi: 10.1104/pp.105.063917

Coelho, C. M., Wu, S., Li, Y., Hunter, B., Dante, R. A., Cui, Y., et al. (2007). Identification of quantitative trait loci that affect endoreduplication in maize endosperm. Theor. Appl. Genet. 115, 1147-1162. doi: 10.1007/s00122-007-0640-z

Collins, C., Dewitte, W., and Murray, J. A. (2012). D-type cyclins control cell division and developmental rate during Arabidopsis seed development. J. Exp. Bot. 63, 3571-3586. doi: 10.1093/jxb/ers015

Costa, L. M., Marshall, E., Tesfaye, M., Silverstein, K. A. T., Mori, M., Umetsu, Y., et al. (2014). Central cell-derived peptides regulate early embryo patterning in flowering plants. Science 344, 168-172. doi: 10.1126/science.1243005

Costas, C., Sanchez, M. D. L., Sequeira-Mendes, J., and Gutierrez, C. (2011). Progress in understanding DNA replication control. Plant Sci. 181, 203-209. doi: 10.1016/j.plantsci.2011.04.020

Dante, R. A., Sabelli, P. A., Nguyen, H. N., Leiva-Neto, J. T., Tao, Y., Lowe, K. S., et al. (2014). Cyclin-dependent kinase complexes in developing maize endosperm: evidence for differential expression and functional specialization. Planta 239, 493-509. doi: 10.1007/s00425-013-1990-1

De Veylder, L., Larkin, J. C., and Schnittger, A. (2011). Molecular control and function of endoreplication in development and physiology. Trends Plant Sci. 16, 624-634. doi: 10.1016/j.tplants.2011. 07.001

Dhillon, S. S., and Miksche, J. P. (1983). DNA, RNA, protein and heterochromatin changes during embryo development and germination of soybean (Glycine max L.). Histochem. J. 15, 21-37. doi: 10.1007/BF01006069

Dilkes, B. P., Dante, R. A., Coelho, C., and Larkins, B. A. (2002). Genetic analyses of endoreduplication in Zea mays endosperm: evidence of sporophytic and zygotic maternal control. Genetics 160, 1163-1177.
Dudits, D., Cserháti, M., Miskolczi, P., and Horváth, G. V. (2007). "The growing family of plant Cyclin-Dependent Kinases with multiple functions in cellular and developmental regulation," in Annual Plant Reviews, Vol. 32, Cell Cycle Control and Plant Development, ed. D. Inzé (Oxford: Blackwell Publishing Ltd), 1-30. doi: 10.1002/9780470988923.ch1

Ebel, C., Mariconti, L., and Gruissem, W. (2004). Plant retinoblastoma homologues control nuclear proliferation in the female gametophyte. Nature 429, 776-780. doi: $10.1038 /$ nature 02637

Edgar, B. A., Zielke, N., and Gutierrez, C. (2014). Endocycles: a recurrent evolutionary innovation for post-mitotic cell growth. Nat. Rev. Mol. Cell Biol. 15, 197-210. doi: $10.1038 / \mathrm{nrm} 3756$

Egli, D. B. (2006). The role of seed in the determination of yield of grain crops. Aust. J. Agric. Res. 57, 1237-1247. doi: 10.1071/AR06133

Eloy, N. B., Gonzalez, N., Van Leene, J., Maleux, K., Vanhaeren, H., De Milde, L., et al. (2012). SAMBA, a plant-specific anaphase-promoting complex/cyclosome regulator is involved in early development and A-type cyclin stabilization. Proc. Natl. Acad. Sci. U.S.A. 109, 13853-13858. doi: 10.1073/pnas.1211418109

Fiume, E., and Fletcher, J. C. (2012). Regulation of Arabidopsis embryo and endosperm development by the polypeptide signaling molecule CLE8. Plant Cell 24, 1000-1012. doi: 10.1105/tpc.111.094839

Folsom, J. J., Begcy, K., Hao, X., Wang, D., and Walia, H. (2014). Rice Fertilization-Independent Endosperm1 regulates seed size under heat stress by controlling early endosperm development. Plant Physiol. 165, 238-248. doi: 10.1104/pp.113.232413

Garcia, D., Fitz Gerald, J. N., and Berger, F. (2005). Maternal control of integument cell elongation and zygotic control of endosperm growth are coordinated to determine seed size in Arabidopsis. Plant Cell 17, 52-60. doi: $10.1105 /$ tpc. 104.027136

Genschik, P., Marrocco, K., Bach, L., Noir, S., and Criqui, M. C. (2013). Selective protein degradation: a rheostat to modulate cell-cycle phase transitions. J. Exp. Bot. 65, 2603-2615. doi: 10.1093/jxb/ert426

Gordon-Kamm, W., Dilkes, B. P., Lowe, K., Hoerster, G., Sun, X., Ross, M., et al. (2002). Stimulation of the cell cycle and maize transformation by disruption of the plant retinoblastoma pathway. Proc. Natl. Acad. Sci. U.S.A. 99, 11975-11980. doi: $10.1073 /$ pnas. 142409899

Grafi, G., Burnett, R. J., Helentjaris, T., Larkins, B. A., Decaprio, J. A., Sellers, W. R., et al. (1996). A maize cDNA encoding a member of the retinoblastoma protein family: involvement in endoreduplication. Proc. Natl. Acad. Sci. U.S.A. 93, 8962-8967. doi: 10.1073/pnas.93.17.8962

Grafi, G., and Larkins, B. A. (1995). Endoreduplication in maize endosperm: involvement of $\mathrm{M}$ phase-promoting factor inhibition and induction of $\mathrm{S}$ phaserelated kinases. Science 269, 1262-1264. doi: 10.1126/science.269.5228.1262

Gruis, D. F., Guo, H., Selinger, D., Tian, Q., and Olsen, O. A. (2006). Surface position, not signaling from surrounding maternal tissues, specifies aleurone epidermal cell fate in maize. Plant Physiol. 141, 898-909. doi: 10.1104/pp.106.080945

Guillon, F., Larre, C., Petipas, F., Berger, A., Moussawi, J., Rogniaux, H., et al. (2012). A comprehensive overview of grain development in Brachypodium distachyon variety Bd21. J. Exp. Bot. 63, 739-755. doi: 10.1093/jxb/err298

Guo, J., Wang, F., Song, J., Sun, W., and Zhang, X. S. (2010). The expression of Orysa; $\mathrm{CycB} 1 ; 1$ is essential for endosperm formation and causes embryo enlargement in rice. Planta 231, 293-303. doi: 10.1007/s00425-009-1051-y

Haughn, G., and Chaudhury, A. (2005). Genetic analysis of seed coat development in Arabidopsis. Trends Plant Sci. 10, 472-477. doi: 10.1016/j.tplants.2005.08.005

Hemerly, A. S., Ferreira, P. C., Van Montagu, M., Engler, G., and Inze, D. (2000). Cell division events are essential for embryo patterning and morphogenesis: studies on dominant-negative cdc2aAt mutants of Arabidopsis. Plant J. 23, 123-130. doi: 10.1046/j.1365-313x.2000.00800.x

Heyman, J., and De Veylder, L. (2012). The anaphase-promoting complex/cyclosome in control of plant development. Mol. Plant 5, 1182-1194. doi: $10.1093 / \mathrm{mp} / \mathrm{sss} 094$

Hu, X., Cheng, X., Jiang, H., Zhu, S., Cheng, B., and Xiang, Y. (2010). Genomewide analysis of cyclins in maize (Zea mays). Genet. Mol. Res. 9, 1490-1503. doi: 10.4238/vol9-3gmr861

Ingouff, M., Jullien, P. E., and Berger, F. (2006). The female gametophyte and the endosperm control cell proliferation and differentiation of the seed coat in Arabidopsis. Plant Cell 18, 3491-3501. doi: 10.1105/tpc.106.047266

Inzé, D., and De Veylder, L. (2006). Cell cycle regulation in plant development. Annu. Rev. Genet. 40, 77-105. doi: 10.1146/annurev.genet.40.110405.090431 
Ishimaru, K., Hirotsu, N., Madoka, Y., Murakami, N., Hara, N., Onodera, H., et al. (2013). Loss of function of the IAA-glucose hydrolase gene TGW6 enhances rice grain weight and increases yield. Nat. Genet. 45, 707-711. doi: 10.1038/ng.2612

Jakoby, M. J., Weinl, C., Pusch, S., Kuijt, S. J., Merkle, T., Dissmeyer, N., et al. (2006). Analysis of the subcellular localization, function, and proteolytic control of the Arabidopsis cyclin-dependent kinase inhibitor ICK1/KRP1. Plant Physiol. 141, 1293-1305. doi: 10.1104/pp.106.081406

Jenik, P. D., Jurkuta, R. E., and Barton, M. K. (2005). Interactions between the cell cycle and embryonic patterning in Arabidopsis uncovered by a mutation in DNA polymerase epsilon. Plant Cell 17, 3362-3377. doi: 10.1105/tpc.105.036889

John, P. C., and Qi, R. (2008). Cell division and endoreduplication: doubtful engines of vegetative growth. Trends Plant Sci. 13, 121-127. doi: 10.1016/j.tplants.2008.01.004

Johnston, A. J., Matveeva, E., Kirioukhova, O., Grossniklaus, U., and Gruissem, W. (2008). A dynamic reciprocal RBR-PRC2 regulatory circuit controls Arabidopsis gametophyte development. Curr. Biol. 18, 1680-1686. doi: 10.1016/j.cub.2008.09.026

Jullien, P. E., Mosquna, A., Ingouff, M., Sakata, T., Ohad, N., and Berger, F. (2008). Retinoblastoma and its binding partner MSI1 control imprinting in Arabidopsis. PLoS Biol. 6:e194. doi: 10.1371/journal.pbio.0060194

Kiesselbach, T. (1949). The Structure and Reproduction of Corn. Lincoln: University of Nebraska.

Kowles, R. V. (2009). The importance of DNA endoreduplication in the developing endosperm of maize. Maydica 54, 387-399.

Kowles, R. V., and Phillips, R. L. (1985). DNA amplification patterns in maize endosperm nuclei during kernel development. Proc. Natl. Acad. Sci. U.S.A. 82, 7010-7014. doi: 10.1073/pnas.82.20.7010

La, H., Li, J., Ji, Z., Cheng, Y., Li, X., Jiang, S., et al. (2006). Genome-wide analysis of cyclin family in rice (Oryza Sativa L.). Mol. Genet. Genomics 275, 374-386. doi: 10.1007/s00438-005-0093-5

Larkins, B. A., Dilkes, B. P., Dante, R. A., Coelho, C. M., Woo, Y. M., and Liu, Y. (2001). Investigating the hows and whys of DNA endoreduplication. J. Exp. Bot. 52, 183-192. doi: 10.1093/jexbot/52.355.183

Lau, S., Slane, D., Herud, O., Kong, J., and Jurgens, G. (2012). Early embryogenesis in flowering plants: setting up the basic body pattern. Annu. Rev. Plant Biol. 63 483-506. doi: 10.1146/annurev-arplant-042811-105507

Leiva-Neto, J. T., Grafi, G., Sabelli, P. A., Dante, R. A., Woo, Y. M., Maddock, S. et al. (2004). A dominant negative mutant of cyclin-dependent kinase A reduces endoreduplication but not cell size or gene expression in maize endosperm. Plant Cell 16, 1854-1869. doi: 10.1105/tpc.022178

Lemontey, C., Mousset-Declas, C., Munier-Jolain, N., and Boutin, J. P. (2000). Maternal genotype influences pea seed size by controlling both mitotic activity during early embryogenesis and final endoreduplication level/cotyledon cell size in mature seed. J. Exp. Bot. 51, 167-175. doi: 10.1093/jexbot/51. 343.167

Li, J., Nie, X., Tan, J. L., and Berger, F. (2013). Integration of epigenetic and genetic controls of seed size by cytokinin in Arabidopsis. Proc. Natl. Acad. Sci. U.S.A. 110, 15479-15484. doi: 10.1073/pnas.1305175110

Lur, H. S., and Setter, T. L. (1993). Role of auxin in maize endosperm development (timing of nuclear DNA endoreduplication, zein expression, and cytokinin). Plant Physiol. 103, 273-280.

Ma, Z., Wu, Y., Jin, J., Yan, J., Kuang, S., Zhou, M., et al. (2013). Phylogenetic analysis reveals the evolution and diversification of cyclins in eukaryotes. Mol. Phylogenet. Evol. 66, 1002-1010. doi: 10.1016/j.ympev.2012.12.007

Mizukami, Y. (2001). A matter of size: developmental control of organ size in plants. Curr. Opin. Plant Biol. 4, 533-539. doi: 10.1016/S1369-5266(00)00212-0

Mizutani, M., Naganuma, T., Tsutsumi, K., and Saitoh, Y. (2010). The syncytiumspecific expression of the Orysa;KRP3 CDK inhibitor: implication of its involvement in the cell cycle control in the rice (Oryza sativa L.) syncytial endosperm. J. Exp. Bot. 61, 791-798. doi: 10.1093/jxb/erp343

Nakai, T., Kato, K., Shinmyo, A., and Sekine, M. (2006). Arabidopsis KRPs have distinct inhibitory activity toward cyclin D2-associated kinases, including plant-specific B-type cyclin-dependent kinase. FEBS Lett. 580, 336-340. doi: 10.1016/j.febslet.2005.12.018

Nowack, M. K., Harashima, H., Dissmeyer, N., Zhao, X., Bouyer, D., Weimer, A. K., etal. (2012). Genetic framework of cyclin-dependent kinase function in Arabidopsis. Dev. Cell 22, 1030-1040. doi: 10.1016/j.devcel. 2012.02.015
Nowack, M. K., Ungru, A., Bjerkan, K. N., Grini, P. E., and Schnittger, A. (2010). Reproductive cross-talk: seed development in flowering plants. Biochem. Soc. Trans. 38, 604-612. doi: 10.1042/bst0380604

Ohto, M. A., Floyd, S. K., Fischer, R. L., Goldberg, R. B., and Harada, J. J. (2009). Effects of APETALA2 on embryo, endosperm, and seed coat development determine seed size in Arabidopsis. Sex. Plant Reprod. 22, 277-289. doi: 10.1007/s00497-009-0116-1

Olsen, O. A. (2004). Nuclear endosperm development in cereals and Arabidopsis thaliana. Plant Cell 16(Suppl.), S214-S227. doi: 10.1105/tpc.017111

Powell, A. E., and Lenhard, M. (2012). Control of organ size in plants. Curr. Biol. 22, R360-R367. doi: 10.1016/j.cub.2012.02.010

Ren, H., Santner, A., Del Pozo, J. C., Murray, J. A., and Estelle, M. (2008). Degradation of the cyclin-dependent kinase inhibitor KRP1 is regulated by two different ubiquitin E3 ligases. Plant J. 53, 705-716. doi: 10.1111/j.1365-313X.2007.03370.x

Rewers, M., and Sliwinska, E. (2012). Endoreduplication intensity as a marker of seed developmental stage in the Fabaceae. Cytometry A 81, 1067-1075. doi: 10.1002/cyto.a.22202

Roodbarkelari, F., Bramsiepe, J., Weinl, C., Marquardt, S., Novak, B., Jakoby, M. J., et al. (2010). Cullin 4-ring finger-ligase plays a key role in the control of endoreplication cycles in Arabidopsis trichomes. Proc. Natl. Acad. Sci. U.S.A. 107, 15275-15280. doi: 10.1073/pnas.1006941107

Sabelli, P. A. (2012a). Replicate and die for your own good: endoreduplication and cell death in the cereal endosperm. J. Cereal Sci. 56, 9-20. doi: 10.1016/j.jcs.2011.09.006

Sabelli, P. A. (2012b). "Seed development: a comparative overview on biology of morphology, physiology, and biochemistry between monocot and dicot plants," in Seed Development: OMICS Technologies toward Improvement of Seed Quality and Crop Yield, eds G. K. Agrawal and R. Rakwal (Amsterdam: Springer), 3-25. doi: 10.1007/978-94-007-4749-4_1

Sabelli, P. A. (2014). "Cell cycle regulation and plant development," in Handbook of Plant and Crop Physiology, 3rd Edn, ed. M. Pessarakli (Boca Raton, FL: CRC Press), 3-32.

Sabelli, P. A., Dante, R. A., Leiva-Neto, J. T., Jung, R., Gordon-Kamm, W. J., and Larkins, B. A. (2005). RBR3, a member of the retinoblastoma-related family from maize, is regulated by the RBR1/E2F pathway. Proc. Natl. Acad. Sci. U.S.A. 102, 13005-13012. doi: 10.1073/pnas.0506160102

Sabelli, P. A., Hoerster, G., Lizarraga, L. E., Brown, S. W., Gordon-Kamm, W. J., and Larkins, B. A. (2009). Positive regulation of minichromosome maintenance gene expression, DNA replication, and cell transformation by a plant retinoblastoma gene. Proc. Natl. Acad. Sci. U.S.A. 106, 4042-4047. doi: 10.1073/pnas.0813329106 Sabelli, P. A., and Larkins, B. A. (2006). Grasses like Mammals? Redundancy and compensatory regulation within the retinoblastoma protein family. Cell Cycle 5, 352-355. doi: 10.4161/cc.5.4.2428

Sabelli, P. A., and Larkins, B. A. (2009a). The contribution of cell cycle regulation to endosperm development. Sex. Plant Reprod. 22, 207-219. doi: 10.1007/s00497009-0105-4

Sabelli, P. A., and Larkins, B. A. (2009b). The development of endosperm in grasses. Plant Physiol. 149, 14-26. doi: 10.1104/pp.108.129437

Sabelli, P. A., and Larkins, B. A. (2009c). Regulation and function of retinoblastomarelated plant genes. Plant Sci. 177, 540-548. doi: 10.1016/j.plantsci.2009.09.012

Sabelli, P. A., Liu, Y., Dante, R. A., Lizarraga, L. E., Nguyen, H. N., Brown, S. W., et al. (2013). Control of cell proliferation, endoreduplication, cell size, and cell death by the retinoblastoma-related pathway in maize endosperm. Proc. Natl. Acad. Sci. U.S.A. 110, E1827-E1836. doi: 10.1073/pnas.1304903110

Schruff, M. C., Spielman, M., Tiwari, S., Adams, S., Fenby, N., and Scott, R. J. (2006). The AUXIN RESPONSE FACTOR 2 gene of Arabidopsis links auxin signalling, cell division, and the size of seeds and other organs. Development 133, 251-261. doi: 10.1242/dev.02194

Sekhon, R. S., Hirsch, C. N., Childs, K. L., Breitzman, M. W., Kell, P., Duvick, S., et al. (2014). Phenotypic and transcriptional analysis of divergently selected maize populations reveals the role of developmental timing in seed size determination. Plant Physiol. 165, 658-669. doi: 10.1104/pp.114.235424

Su'udi, M., Cha, J. Y., Ahn, I.-P., Kwak, Y.-S., Woo, Y.-M., and Son, D. (2012a). Functional characterization of a B-type cell cycle switch 52 in rice (OsCCS52B). Plant Cell Tissue Organ Cult. 111, 101-111. doi: 10.1007/s11240-012-0176-Z

Su'udi, M., Cha, J. Y., Jung, M. H., Ermawati, N., Han, C. D., Kim, M. G., et al. (2012b). Potential role of the rice OsCCS52A gene in endoreduplication. Planta 235, 387-397. doi: 10.1007/s00425-011-1515-8 
Sugimoto-Shirasu, K., and Roberts, K. (2003). "Big it up": endoreduplication and cell-size control in plants. Curr. Opin. Plant Biol. 6, 544-553. doi: 10.1016/j.pbi.2003.09.009

Sun, Y., Dilkes, B. P., Zhang, C., Dante, R. A., Carneiro, N. P., Lowe, K. S., et al. (1999a). Characterization of maize (Zea mays L.) Weel and its activity in developing endosperm. Proc. Natl. Acad. Sci. U.S.A. 96, 4180-4185. doi: 10.1073/pnas.96.7.4180

Sun, Y., Flannigan, B. A., and Setter, T. L. (1999b). Regulation of endoreduplication in maize (Zea mays L.) endosperm. Isolation of a novel B1-type cyclin and its quantitative analysis. Plant Mol. Biol. 41, 245-258. doi: 10.1023/A:1006315625486

Trafford, K., Haleux, P., Henderson, M., Parker, M., Shirley, N. J., Tucker, M. R., et al. (2013). Grain development in Brachypodium and other grasses: possible interactions between cell expansion, starch deposition, and cell-wall synthesis. $J$. Exp. Bot. 64, 5033-5047. doi: 10.1093/jxb/ert292

Tuteja, N., Tran, N. Q., Dang, H. Q., and Tuteja, R. (2011). Plant MCM proteins: role in DNA replication and beyond. Plant Mol. Biol. 77, 537-545. doi: 10.1007/s11103-011-9836-3

Van Daele, I., Gonzalez, N., Vercauteren, I., De Smet, L., Inzé, D., Roldan-Ruiz, I., et al. (2012). A comparative study of seed yield parameters in Arabidopsis thaliana mutants and transgenics. Plant Biotechnol. J. 10, 488-500. doi: 10.1111/j.14677652.2012.00687.x

Van Leene, J., Boruc, J., De Jaeger, G., Russinova, E., and De Veylder, L. (2011). A kaleidoscopic view of the Arabidopsis core cell cycle interactome. Trends Plant Sci. 16, 141-150. doi: 10.1016/j.tplants.2010.12.004

van Zanten, M., Koini, M. A., Geyer, R., Liu, Y., Brambilla, V., Bartels, D., et al. (2011). Seed maturation in Arabidopsis thaliana is characterized by nuclear size reduction and increased chromatin condensation. Proc. Natl. Acad. Sci. U.S.A. 108, 20219-20224. doi: 10.1073/pnas. 1117726108

Verkest, A., Manes, C. L., Vercruysse, S., Maes, S., Van Der Schueren, E., Beeckman, T., et al. (2005). The cyclin-dependent kinase inhibitor KRP2 controls the onset of the endoreduplication cycle during Arabidopsis leaf development through inhibition of mitotic CDKA;1 kinase complexes. Plant Cell 17, 1723-1736. doi: 10.1105/tpc.105.032383

Vilhar, B., Kladnik, A., Blejec, A., Chourey, P. S., and Dermastia, M. (2002). Cytometrical evidence that the loss of seed weight in the miniaturel seed mutant of maize is associated with reduced mitotic activity in the developing endosperm. Plant Physiol. 129, 23-30. doi: 10.1104/pp.001826

Vlieghe, K., Boudolf, V., Beemster, G. T., Maes, S., Magyar, Z., Atanassova, A., et al. (2005). The DP-E2F-like gene DEL1 controls the endocycle in Arabidopsis thaliana. Curr. Biol. 15, 59-63. doi: 10.1016/j.cub.2004.12.038

Walley, J. W., Shen, Z., Sartor, R., Wu, K. J., Osborn, J., Smith, L. G., et al. (2013). Reconstruction of protein networks from an atlas of maize seed proteotypes. Proc. Natl. Acad. Sci. U.S.A. 110, E4808-E4817. doi: 10.1073/pnas.1319113110

Wang, G., Kong, H., Sun, Y., Zhang, X., Zhang, W., Altman, N., et al. (2004). Genome-wide analysis of the cyclin family in Arabidopsis and comparative phylogenetic analysis of plant cyclin-like proteins. Plant Physiol. 135, 1084-1099. doi: 10.1104/pp.104.040436

Wang, H., Zhou, Y., Bird, D. A., and Fowke, L. C. (2008). Functions, regulation and cellular localization of plant cyclin-dependent kinase inhibitors. J. Microsc. 231, 234-246. doi: 10.1111/j.1365-2818.2008.02039.x

Wang, Y., Hou, Y., Gu, H., Kang, D., Chen, Z., Liu, J., et al. (2012). The Arabidopsis APC4 subunit of the anaphase-promoting complex/cyclosome (APC/C) is critical for both female gametogenesis and embryogenesis. Plant J. 69, 227-240. doi: 10.1111/j.1365-313X.2011.04785.x
Wang, Y., Hou, Y., Gu, H., Kang, D., Chen, Z. L., Liu, J., et al. (2013). The Arabidopsis anaphase-promoting complex/cyclosome subunit 1 is critical for both female gametogenesis and embryogenesis(F). J. Integr. Plant Biol. 55, 64-74. doi: 10.1111/jipb.12018

Weimer, A. K., Nowack, M. K., Bouyer, D., Zhao, X., Harashima, H., Naseer, S., et al. (2012). Retinoblastoma related 1 regulates asymmetric cell divisions in Arabidopsis. Plant Cell 24, 4083-4095. doi: 10.1105/tpc.112.104620

Weinl, C., Marquardt, S., Kuijt, S. J., Nowack, M. K., Jakoby, M. J., Hulskamp, M., et al. (2005). Novel functions of plant cyclin-dependent kinase inhibitors, ICK1/KRP1, can act non-cell-autonomously and inhibit entry into mitosis. Plant Cell 17, 1704-1722. doi: 10.1105/tpc.104.030486

Willemsen, V., Wolkenfelt, H., De Vrieze, G., Weisbeek, P., and Scheres, B. (1998). The HOBBIT gene is required for formation of the root meristem in the Arabidopsis embryo. Development 125, 521-531.

Wu, C.-Y., Rolfe, P. A., Gifford, D. K., and Fink, G. R. (2010). Control of transcription by cell size. PLoS Biol. 8:e1000523. doi: 10.1371/journal.pbio.1000523

Xie, Q., Sanz-Burgos, A. P., Hannon, G. J., and Gutierrez, C. (1996). Plant cells contain a novel member of the retinoblastoma family of growth regulatory proteins. EMBO J. 15, 4900-4908.

Yi, D., Kamei, C. L., Cools, T., Vanderauwera, S., Takahashi, N., Okushima, Y., et al. (2014). The Arabidopsis SIAMESE-RELATED Cyclin-Dependent Kinase Inhibitors SMR5 and SMR7 regulate the DNA damage checkpoint in response to reactive oxygen species. Plant Cell 26, 296-309. doi: 10.1105/tpc.113.118943

Young, T. E., and Gallie, D. R. (2000). Programmed cell death during endosperm development. Plant Mol. Biol. 44, 283-301. doi: 10.1023/ A:1026588408152

Yu, Y., Steinmetz, A., Meyer, D., Brown, S., and Shen, W. H. (2003). The tobacco A-type cyclin, Nicta;CYCA3;2, at the nexus of cell division and differentiation. Plant Cell 15, 2763-2777. doi: 10.1105/tpc.015990

Zhou, Y., Li, G., Brandizzi, F., Fowke, L. C., and Wang, H. (2003). The plant cyclin-dependent kinase inhibitor ICK1 has distinct functional domains for in vivo kinase inhibition, protein instability and nuclear localization. Plant J. 35, 476-489. doi: 10.1046/j.1365-313X.2003.01821.x

Zhou, Y., Zhang, X., Kang, X., Zhao, X., Zhang, X., and Ni, M. (2009). SHORT HYPOCOTYL UNDER BLUE1 associates with MINISEED3 and HAIKU2 promoters in vivo to regulate Arabidopsis seed development. Plant Cell 21, 106-117. doi: $10.1105 /$ tpc. 108.064972

Conflict of Interest Statement: The authors declare that the research was conducted in the absence of any commercial or financial relationships that could be construed as a potential conflict of interest.

Received: 18 June 2014; accepted: 05 September 2014; published online: 23 September 2014.

Citation: Dante RA, Larkins BA and Sabelli PA (2014) Cell cycle control and seed development. Front. Plant Sci. 5:493. doi: 10.3389/fpls.2014.00493

This article was submitted to Plant Evolution and Development, a section of the journal Frontiers in Plant Science.

Copyright $\odot 2014$ Dante, Larkins and Sabelli. This is an open-access article distributed under the terms of the Creative Commons Attribution License (CC BY). The use, distribution or reproduction in other forums is permitted, provided the original author(s) or licensor are credited and that the original publication in this journal is cited, in accordance with accepted academic practice. No use, distribution or reproduction is permitted which does not comply with these terms. 